\title{
SPLIT-THICKNESS SKIN EXCISION IN SEVERE OPEN FRACTURES
}

\author{
I. ZIV, A. ZELIGOWSKI, R. MOSHEIFF, J. LOWE, M. R. WEXLER, D. SEGAL
}

\section{From the Hadassah University Hospital and the Hebrew University Medical School, Jerusalem}

\begin{abstract}
Split-thickness skin excision can be used as a one-stage procedure for the accurate diagnosis of flap viability and the immediate treatment of friction-avulsion injuries in severe open fractures. After cleaning the wound, the avulsed flap is temporarily sutured back to its original bed and a split thickness graft is taken from it and meshed to a 1:3 ratio. Surface dermal capillary bleeding then serves as an indicator of viability, clearly displaying a line for the excision of devascularised skin and correlating well with a concomitant fluorescein test. The wounds are re-opened and, after fixation of the fracture, the viable part of the flap is returned to its original bed and the remaining defects are covered with the meshed graft.

We have treated 16 patients with extensive degloving injuries in this way, 15 needing only the single surgical procedure. All retained flaps survived, no other donor sites were needed and the split-thickness grafts took with $90 \%$ to $100 \%$ success.
\end{abstract}

Open fractures associated with friction-avulsion of the soft tissues are very severe injuries and have a high complication rate (Gustilo and Anderson 1976; Byrd, Cierny and Tebbetts 1981; Byrd, Spicer and Cierny 1985). Torsional and compressive forces may separate and tear the skin, muscles and neurovascular structures from their underlying bed (MacCollum 1938; Entin 1955; Prendiville and Lewis 1955). The result is partial devascularisation of skin and muscle flaps.

Awareness of the importance of the viability of these residual flaps and their preservation increased after McGrouther and Sully (1980) had recommended the use of the fluorescein test (McCraw, Myers and Shanklin 1977; Kalisman et al. 1978). This test is one of the most commonly used methods of determining skin viability, but its interpretation may be difficult and the dye can occasionally provoke a hypersensitivity reaction (McCraw et al. 1977).

We present a simple one-stage procedure for the immediate management of the soft tissues and the open fractures produced by friction-avulsion injury.

I. Ziv, MD, FRCS(C), Senior Orthopaedic Surgeon

A. Zeligowski, MD, Senior Plastic Surgery Resident

R. Mosheiff, MD, Assistant Resident in Orthopaedic Surgery

J. Lowe, MD, Senior Orthopaedic Surgeon

M. R. Wexler, MD, Professor of Plastic and Maxillofacial Surgery

D. Segal, MD, Professor of Orthopaedic Surgery

Hadassah University Hospital, PO Box 12010, Jerusalem 91120, Israel.

(C) 1988 British Editorial Society of Bone and Joint Surgery $0301-620 X / 88 / 1008 \$ 2.00$

J Bone Joint Surg [Br] 1988;70-B:23-6.

\section{TECHNIQUE OF OPERATION}

At operation culture swabs are taken of all wounds which are then copiously irrigated with saline and subjected to meticulous debridement. Avulsed flaps are then sutured back in their original anatomical position, using inverted intradermal sutures (Zeligowski and Ziv 1987). The fluorescein test is performed and the borders of devascularisation are marked with methylene blue and pinprick tattooing. A split-thickness skin excision (STSE) is used to take a graft from the entire flap (Fig. 1). On the flap surface, dermal capillary bleeding indicates the viable part of the flap; this correlated well with the fluorescein test. Non-bleeding devitalised areas are then excised.

All the fascial compartments in the extremity are decompressed by longitudinal incisions and the muscle and neurovascular bundles are inspected. Muscle viability is determined by colour, turgor, bleeding and

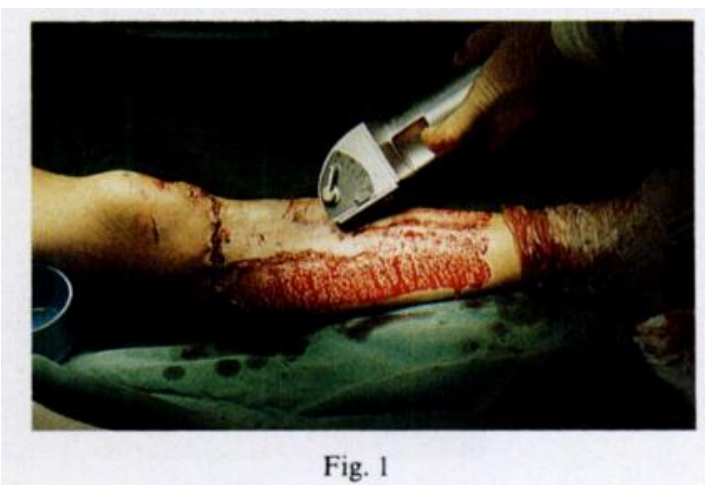

Technique of split-thickness skin excision on an avulsion flap which has been temporarily sutured in place. 
contractility. All crushed and dead muscles are excised. Free fragments of cortical bone are removed if this does not jeopardise stability.

The reparative part of the one-stage procedure starts with fracture reduction. Fractures are stabilised by external and internal fixation using inter-fragmentary compression screws to hold fragments in continuity and buttressing the reduction with an external fixator. Available viable muscles are rotated or transposed to cover denuded bone. The remaining viable skin flaps are then defatted and sutured back into position under minimal tension. The split-thickness skin graft, taken from the degloved flaps, is meshed $(1: 3)$ and used as graft to cover all the remaining exposed areas. The grafts are secured by peripheral sutures or clips; petroleum gauze and wet cotton fluffs are applied to improve the skin graft moulding. The limb is then immobilised, using plaster splints as necessary.

Postoperatively, the extremity is elevated. Intravenous cephalosporines are given during the operation and for an additional 10 days. The wounds are inspected on the third postoperative day. If any additional skin graft is needed, this is applied in the ward under aseptic conditions, using remnants of the original harvest which have been preserved in a refrigerator.

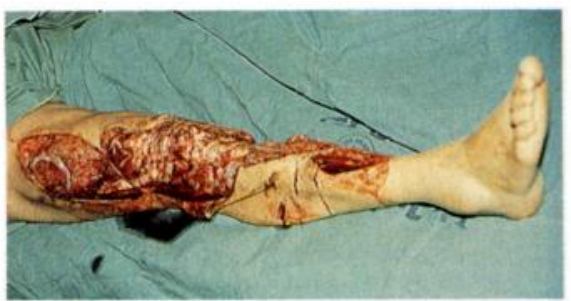

Fig. 2

\section{ILLUSTRATIVE CASE REPORTS}

Case 1. A 32-year-old physical education teacher suffered a severe compound injury to her left leg in a motorcycle accident (Fig. 2) with an open fracture of the lateral femoral condyle and a complete tear of the quadriceps. Four hours after admission, cleaning and debridement were performed, the wounds were temporarily sutured and STSE was carried out (Figs 3 and 4) followed by excision of all non-viable skin. Loose bone fragments were removed from the knee and the quadriceps was repaired. All compartments of the lower leg were decompressed and the remaining open wounds were covered with meshed skin graft (Fig. 5). Continuous passive movement was started, using a range of movement that avoided tension on the quadriceps repair. At 10 days, all the wounds had healed primarily. Three weeks after the injury the patient was discharged home with an active range of knee movement from $0^{\circ}$ to $70^{\circ}$. Six weeks postoperatively she could straight-leg raise with $20^{\circ}$ extensor lag and flex to $95^{\circ}$ (Figs 6 and 7).

Case 2. A 21-year-old man presented with a severe open fracture of the left humerus and a complete radial nerve palsy, after his arm had been caught between machine rollers (Fig. 8). Some large bone fragments were brought separately in a plastic bag. There were two main skin flaps, proximal and distal, and the proximal one had a large hole at its base (Fig. 9).

At operation the wounds were thoroughly irrigated, cleaned and temporarily sutured; STSE was then performed. In this case the viable flap was shown to be larger than that indicated by the fluorescein test. The radial nerve ends were trimmed, transposed anteriorly and repaired without tension. The humerus was shortened by $1 \mathrm{~cm}$, the free bony fragments being autoclaved and replaced. Inter-fragmentary compression screws and an external fixator were used (Fig. 10). Parts of

Case 1. Figure 2 - Severe open injury with circumferential degloving, except for a narrow posterior bridge. Figure 3 - The flaps have been sutured to their original bed. Figure 4 - The lateral side of the thigh and leg after the STSE. Note the non-bleeding skin of the proximal thigh flap and the anterior knee and leg flaps. Figure 5- Leg after debridement and repair, the excision of avascular skin and the application of meshed skin graft.

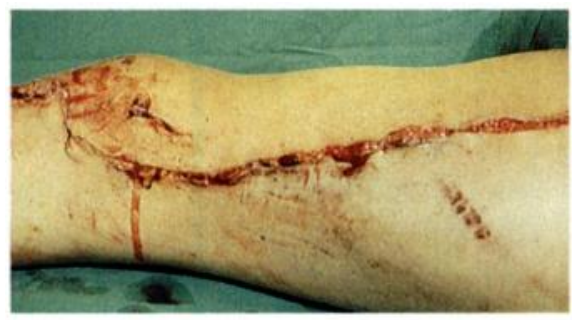

Fig. 3

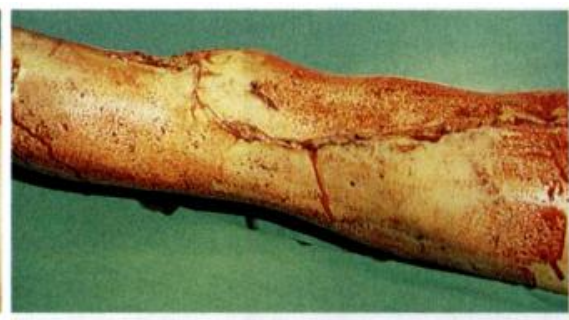

Fig. 4

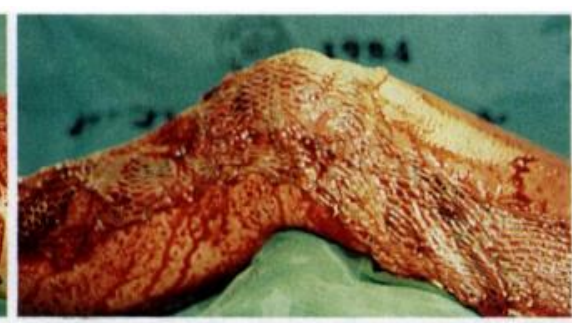

Fig. 5

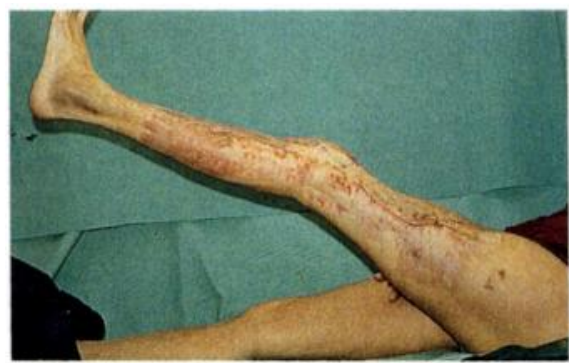

Fig. 6

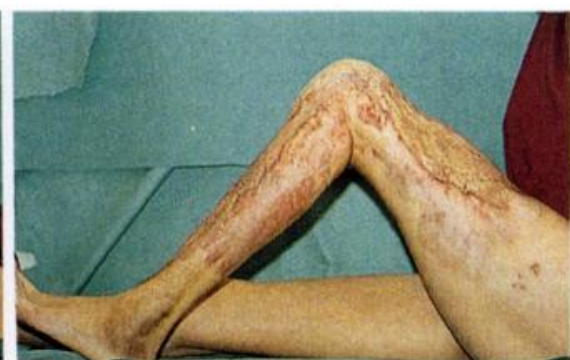

Fig. 7

Case 1. Range of movement six weeks after the injury. 


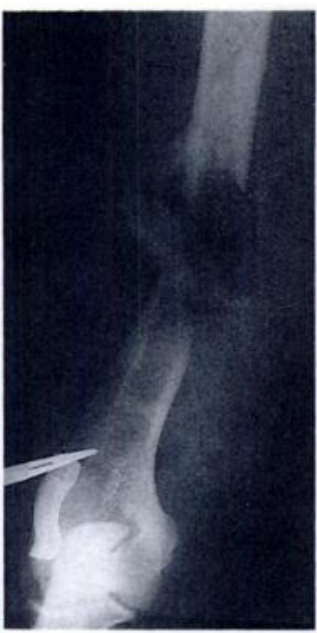

Fig. 8

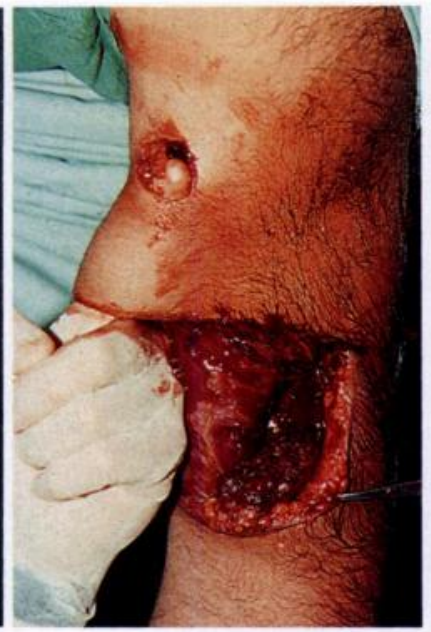

Fig. 9

Case 2. Radiograph and operative view of open comminuted midshaft fracture of the humerus. The proximal skin flap was avulsed from more than two-thirds of the circumference of the arm.

the triceps and biceps muscles were transposed to cover the fracture. The viable parts of the flaps were sutured to the surrounding soft tissues and the meshed graft applied to complete the skin cover. Postoperative healing was satisfactory and the skin graft took well with no further flap necrosis. The patient was discharged two weeks after admission and was able to use his hand with a dynamic extension splint. The external fixator was removed six weeks after operation. Three months after the injury the brachioradialis and supinator muscles were functioning (Fig. 11). Delayed union at the proximal part of the segmental fracture needed a late intra-medullary fixation, but healed in seven months.

Case 3. A 27-year-old man was hit by a car and sustained a very severe open fracture of the left tibia and fibula (Figs 12 and 13). After irrigation and debridement, reduction was secured with multiple interfragmentary screws and an external fixator (Fig. 14). The wound edges were approximated for the STSE by which skin graft was harvested. Soleus muscle was transposed to cover the fracture and meshed graft

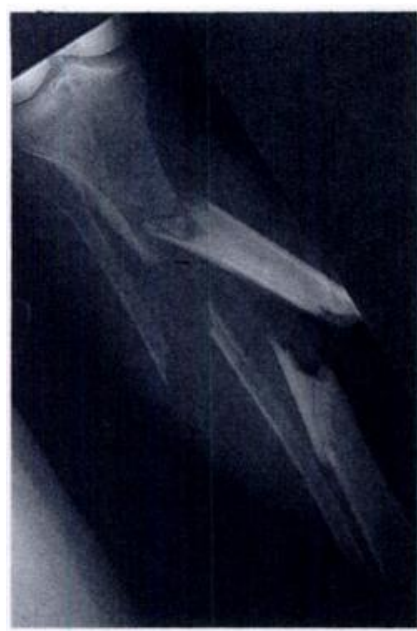

Fig. 12

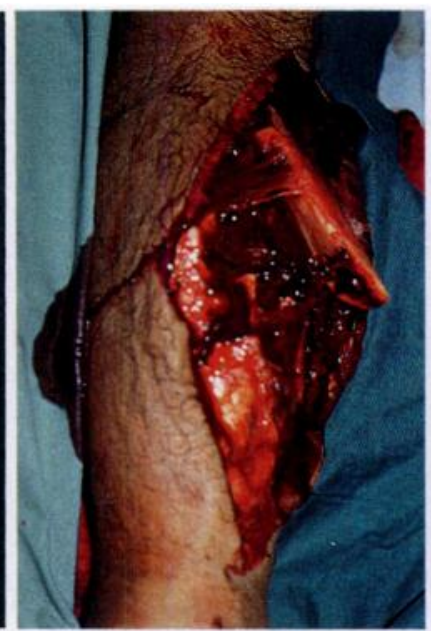

Fig. 13

Radiograph and photograph of an open fracture of the left tibia and fibula. One large fragment still has a muscle pedicle.

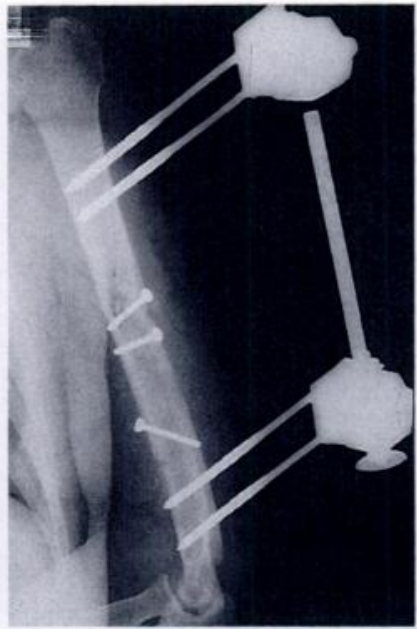

Fig. 10

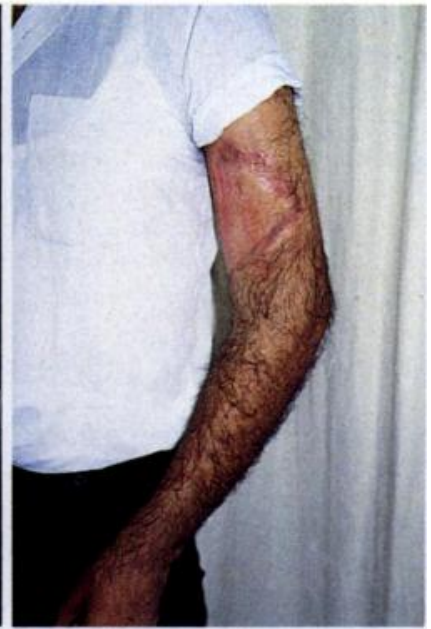

Fig. 11
Figure 10 - Post-reduction radiograph. Figure 11 - Appearance at three months.

was applied over the exposed muscles (Fig. 15). The skin graft took well and the wounds healed uneventfully.

Other cases. Another 14 severe open fractures in 13 patients have been treated by this technique. Twelve fractures were of Type III or Type IV (Gustilo and Anderson 1976; Byrd et al. 1981) and two were degloving amputations, one below the elbow and one at the hip. In all the patients, the avulsion flaps involved more than two-thirds of the limb circumference, and all the wounds were over $10 \mathrm{~cm}$ in length. Two children had unstable open pelvic fractures with severe perineal injuries, but the majority were leg fractures caused by motor-vehicle accidents.

Patients' ages were from 2 to 56 years (mean 17.8 years) and they have been followed up for an average of 9.3 months, with prospective documentation. In seven of these patients the STSE test was compared to the fluorescein test. In three cases STSE helped to preserve flaps by $3 \mathrm{~cm}$ more than indicated by fluorescein. In general the devascularised area varied between $25 \%$ and $50 \%$ of the surface area of the degloved

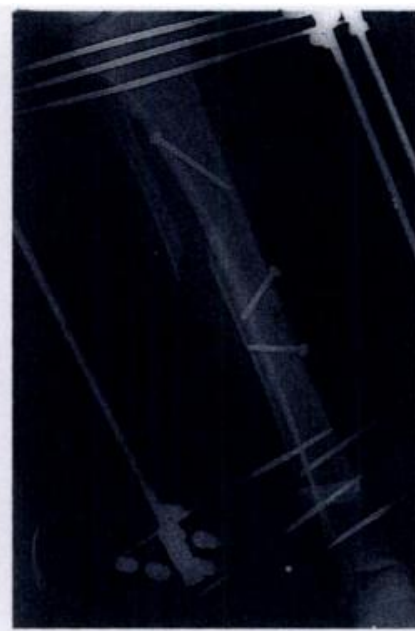

Fig. 14

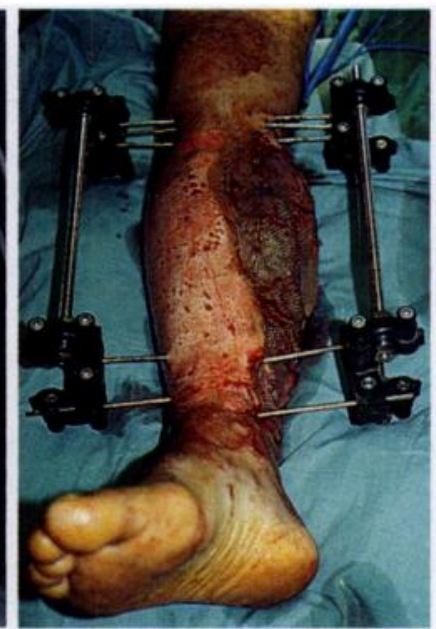

Fig. 15
Postoperative radiograph and photograph. Meshed skin graft is covering the transposed muscles. Dermal bleeding can be seen at the donor site on the anterior flap. 
flaps. In one patient only, some necrotic flap edges appeared five days after operation. The area was small enough to allow bedside excision and grafting with spare meshed skin. One patient with severe crushing of the foot developed a superficial Pseudomonas infection; this healed after appropriate antibiotic therapy and the bedside application of more skin grafts. No other complications of soft tissue healing were seen in any of the other patients, and uneventful healing occurred within 7 to 14 days. Only one patient required more than the single procedure in the operating theatre on admission.

\section{DISCUSSION}

The treatment of severe open fractures is difficult and complicated; we report the use of a one-stage soft-tissue procedure which was successful in 16 consecutive cases. Damage to the blood supply of the fractured bone and the surrounding soft tissue correlates well with complications such as non-union and infection (Gustilo and Anderson 1976; Byrd et al. 1985), and it is well recognised that necrotic tissues should be widely excised. Yet without adequate soft-tissue cover bony healing is impaired. In friction-avulsion injuries large flaps of soft tissue are often partially viable. Total flap excision (Kudsk, Sheldon and Walton 1981) should be avoided: the viable parts of the skin flaps should be preserved because they provide good cover for muscle and bone.

The need for the early detection of avascularity led to the fluorescein test (McCraw et al. 1977; McGrouther and Sully 1980). Both papers reported similar results with fluorescein and the marginal bleeding test, but admitted that there could be up to $3 \mathrm{~cm}$ difference between the original fluorescein line and the actual margin of devascularisation. The inexperienced surgeon may not recognise that mottled fluorescent areas will survive (Kudsk et al. 1981; Byrd et al. 1985). Bruises may give areas which fluoresce poorly but remain viable. Fluorescein itself may produce vomiting, nausea and an anaphylactoid reaction (McGrouther and Sully 1980).

Split thickness skin excision is a commonly practiced technique. When it is applied to avulsed flaps, it produces sharp delineation between bleeding and nonbleeding dermis. Skin excision along this line of demarcation permits the preservation of the maximum amount of viable skin. Meshed split skin from the whole of the flaps frequently provides enough graft, and no other donor site is required.

It is important that flap excision be performed early. Revascularisation of skin flaps caused by frictionavulsion is almost impossible because of the paucity of direct cutaneous vessels, so there is no benefit to be gained by waiting (McGrouther and Sully 1980). Longstanding anoxia of the margins of such a flap leads to increased concentrations of oxygen-derived free radicals and to the release of lysosomal proteases. This may start a vicious cycle of cell membrane damage and intercellular oedema that causes the necrosis to spread towards the base of the flap (Fantone and Ward 1982). Kudsk et al. (1981) suggested excision of the whole of such a flap and found no difference between the results of grafting full- thickness or split-thickness skin. The full-thickness graft gave better cosmetic results but prevented drainage and created haematomata. Haematoma-induced necrosis is believed to be mediated by free-radical mechanisms (Angel et al. 1986). In contrast, meshed split skin grafts prevent haematoma formation and act as an excellent biological dressing.

The venous drainage of a flap is frequently disturbed in severe avulsion injuries and we feel that split-thickness skin excision may assist in decongesting the flap, thereby improving its cellular blood supply by decreasing the resistance in its microcirculation.

Conclusions. One-stage split-thickness skin excision is an adjunct to the fluorescein test for the immediate softtissue management of friction-avulsion injuries associated with severe open fractures. The accurate delineation of avascular areas requires that it be performed early after admission. The technique is simple. Split-thickness skin is excised from the entire flap after it has been sutured to its original or anatomical bed (Zeligowski and Ziv 1987) and the freshly excised grafts are meshed 1:3 and used as biological dressings. Inspection of the donor sites was a reliable technique for the diagnosis of flap viability, allowing accurate excision with maximal preservation of tissue. Both healing and rehabilitation were faster, reducing the average stay in hospital.

\section{REFERENCES}

Angel MF, Narayanan K, Swartz WM, et al. The etiologic role of free radicals in hematoma-induced flap necrosis. Plast Reconstr Surg 1986;77:795-801.

Byrd HS, Cierny G III, Tebbetts JB. The management of open tibial fractures with associated soft-tissue loss: external pin fixation with early flap coverage. Plast Reconstr Surg $1981 ; 68: 73-9$.

Byrd HS, Spicer TE, Ciemey G III. Management of open tibial fractures. Plast Reconstr Surg 1985;76:719-28.

Entin MA. Roller and wringer injuries: clinical and experimental studies. Plast Reconstr Surg 1955;15:290-312.

Fantone JC, Ward PA. Review article: role of oxygen-derived free radicals and metabolites in leukocyte-dependent inflammatory reactions. Am J Pathol 1982;107:397-418.

Gustilo RB, Anderson JT. Prevention of infection in the treatment of one thousand and twenty-five open fractures of long bones: retrospective and prospective analysis. J Bone Joint Surg [Am] $1976 ; 58-A: 453-8$.

Kalisman M, Wexler MR, Yeschua R, Neuman Z. Treatment of extensive avulsions of skin and subcutaneous tissues. $J$ Dermatol Surg Oncol 1978;4:322-7.

Kudsk KA, Sheldon GF, Walton RL. Degloving injuries of the extremities and torso. J Trauma $1981 ; 21: 835-9$.

MacCollum DW. Wringer arm: report of 26 cases. $N$ Engl J Med $1938 ; 218: 549-54$.

McCraw JB, Myers B, Shanklin KD. The value of fluorescein in predicting the viability of arterialized flaps. Plast \& Reconstr Surg 1977;60:710-9.

McGrouther DA, Sully L. Degloving injuries of the limbs: long-term review and management based on whole-body fluorescence. $\mathrm{Br} J$ Plast Surg 1980;33:9-24.

Prendiville JB, Lewis E. Pneumatic-tyre torsion avulsion injury. Br $J$ Surg 1955;42:582-7.

Zeligowski AA, Ziv I. How to harvest skin graft from the avulsed flap in degloving injuries. Ann Plast Surg 1987;19:89-90. 